\title{
Hippocampal volumes predict risk of dementia with Lewy bodies in mild cognitive impairment OPEN
}

Kejal Kantarci, MD, MS

Timothy Lesnick, MS

Tanis J. Ferman, PhD

Scott A. Przybelski

Bradley F. Boeve, MD

Glenn E. Smith, PhD

Walter K. Kremers, PhD

David S. Knopman, MD

Clifford R. Jack, Jr., MD

Ronald C. Petersen, MD, $\mathrm{PhD}$

Correspondence to

Dr. Kantarci:

kantarci.kejal@mayo.edu

Supplemental data at Neurology.org

\section{ABSTRACT}

Objective: To predict the risk of probable dementia with Lewy bodies (DLB) competing with Alzheimer disease (AD) dementia by hippocampal volume (HV) in patients with mild cognitive impairment (MCl) with impairments in amnestic or nonamnestic cognitive domains.

Methods: Patients with MCI $(n=160)$ from the Mayo Clinic Alzheimer's Disease Research Center, who participated in an MRI study at baseline from 2005 to 2014, were followed with approximately annual clinical evaluations. HVs were analyzed from 3T MRIs using FreeSurfer (5.3). Hippocampal atrophy was determined from the most normal 10th percentile of the measurement distributions in a separate cohort of clinically diagnosed patients with AD dementia. The subdistribution hazard ratios for progression to probable DLB and AD dementia were estimated by taking into account the competing risks.

Results: During a median (range) follow-up of 2.0 (0.7-8.1) years, 20 (13\%) patients with $\mathrm{MCl}$ progressed to probable DLB, and 61 (38\%) progressed to AD dementia. The estimated subdistribution hazard ratio (95\% confidence interval) for normal $\mathrm{HV}$ relative to hippocampal atrophy for progression to $A D$ dementia was $0.56(0.34-0.91 ; p=0.02)$ after taking into account the competing risks. The estimated hazard ratio for normal HV relative to hippocampal atrophy for progression to probable DLB was $4.22(1.42-12.6 ; p=0.01)$ after adjusting for age and after including the $\mathrm{MCl}$ subtype in the model.

Conclusions: Preserved hippocampal volumes are associated with increased risk of probable DLB competing with $A D$ dementia in patients with $\mathrm{MCl}$. Preservation of HV may support prodromal DLB over $A D$, particularly in patients with $\mathrm{MCl}$ with nonamnestic features. Neurology ${ }^{\circledR} 2016 ; 87: 2317-2323$

\section{GLOSSARY}

AD = Alzheimer disease; DLB = dementia with Lewy bodies; DSM-IV = Diagnostic and Statistical Manual of Mental Disorders, 4th edition; $\mathbf{H V a}=$ hippocampal volume adjusted for total intracranial volume; $\mathbf{M C l}=$ mild cognitive impairment; NIA = National Institute on Aging; RBD = REM sleep behavior disorder.

Identifying patients with mild cognitive impairment (MCI) who are at risk for dementia with Lewy bodies (DLB) is critical for early interventions. Amnestic subtype of MCI has been established on clinical grounds in order to identify individuals who are at risk for Alzheimer disease (AD) dementia. ${ }^{1,2}$ Patients with MCI who have impairments in nonamnestic cognitive domains may be at an increased risk of DLB. ${ }^{3,4}$ We have previously demonstrated that the competing risk of progression to probable $\mathrm{DLB}$ vs $\mathrm{AD}$ is higher in patients with nonamnestic MCI compared to amnestic MCI. ${ }^{5}$

Hippocampal volumes on antemortem MRI are preserved in patients with DLB who have little or no additional AD pathology at autopsy. ${ }^{6-8}$ Hippocampal volumes are lower in patients with DLB with increasing Braak neurofibrillary tangle stage regardless of the severity of Lewy

\footnotetext{
From the Departments of Radiology (K.K., C.R.J.), Health Sciences Research (T.L., S.A.P., W.K.K.), and Neurology (B.F.B., D.S.K., R.C.P.), Mayo Clinic, Rochester, MN; Department of Psychology and Psychiatry (T.J.F.), Mayo Clinic Jacksonville; and Department of Psychology (G.E.S.), University of Florida, Gainesville.

Go to Neurology.org for full disclosures. Funding information and disclosures deemed relevant by the authors, if any, are provided at the end of the article. The Article Processing Charge was paid by the authors.

This is an open access article distributed under the terms of the Creative Commons Attribution-NonCommercial-NoDerivatives License 4.0 (CC BY-NC-ND), which permits downloading and sharing the work provided it is properly cited. The work cannot be changed in any way or used commercially without premission from the journal.
} 
body disease pathology. ${ }^{7}$ Furthermore, while hippocampal phospho-tau burden is associated with hippocampal atrophy, $\alpha$-synuclein burden does not appear to influence the global hippocampal volume in patients with Lewy body pathology. ${ }^{9}$ Therefore preserved hippocampal volumes may predict progression to $\mathrm{DLB}$ vs $\mathrm{AD}$ in MCI.

Our objectives were two fold: (1) To determine whether the risk of probable DLB accounting for progression to $\mathrm{AD}$ dementia is associated with hippocampal volume in patients with MCI, broadly defined with impairments in amnestic or nonamnestic cognitive domains; and (2) To determine whether MCI subtype and hippocampal volume would independently contribute to predicting the risk of probable $\mathrm{DLB}$ vs $\mathrm{AD}$ in $\mathrm{MCI}$.

METHODS Participants. Consecutive patients with MCI $(n=160)$ from the Mayo Clinic Alzheimer's Disease Research Center participated in an MRI study during October 2005 to January 2014 and were followed approximately annually with clinical evaluations and neuropsychological testing. To be included, the patients had to have a diagnosis of MCI with at least one clinical follow-up evaluation by the end of January 2015. Diagnosis was determined by a consensus committee including the neurologist, neuropsychologist, and the nurse who evaluated each participant. Patients with known neurologic diseases such as epilepsy, brain tumors, or substance abuse that may impact cognitive function were excluded.

The operational definition of MCI was based on clinical judgment through a history from the patient and for the majority of patients from an informant. Published criteria were used for the diagnosis: $\operatorname{cog}$ nitive complaint, cognitive function not normal for age, decline in cognition, essentially normal functional activities, no dementia. ${ }^{10}$ In addition, patients with MCI were classified into 1 of $4 \mathrm{MCI}$ subtypes $^{10}$ : (1) amnestic MCI single-domain, if the impairment was only in the memory domain; (2) amnestic MCI multiple-domain, if the impairment was in the memory domain and one or more nonmemory domains such as language, attention/executive function, and visuospatial processing; (3) nonamnestic MCI single-domain, if the impairment was in one nonmemory domain and memory was relatively preserved; and (4) nonamnestic MCI multiple-domain, if the impairment was in more than one nonmemory domain with relative preservation of memory. We grouped patients with single and multiple-domain nonamnestic MCI because of the small number of patients with nonamnestic MCI multiple-domain $(\mathrm{n}=9)$.

Diagnosis of dementia was based on DSM-IV criteria, diagnosis of probable $\mathrm{AD}$ dementia was based on National Institute on Aging (NIA)-Reagan criteria, ${ }^{11}$ although all also fulfilled the NIA-Alzheimer's Association clinical criteria, ${ }^{12}$ and diagnosis of probable DLB was based on the 3rd Consortium Criteria. ${ }^{13}$ Hippocampal preservation on MRI is not a core or supportive feature of these criteria, and therefore does not contribute to the diagnosis of probable DLB. The clinical characteristics of DLB were assessed in the following manner: presence of parkinsonism was assessed through the Unified Parkinson's Disease Rating Scale part III; visual hallucinations were characterized by being fully formed, not restricted to a single episode, and not related to another medical issue, treatment, or advanced dementia; fluctuations were considered to be present if patients scored 3 to 4 on the Mayo Fluctuations Questionnaire $^{14}$; and probable REM sleep behavior disorder (RBD) was diagnosed through The Mayo Sleep Questionnaire validated in a polysomnography-confirmed sample from the community, which revealed a sensitivity of $100 \%$ and specificity of $95 \%{ }^{15}$ using published criteria for the diagnosis of RBD as the gold standard. ${ }^{16}$

MRI All participants underwent MRI examinations at 3T. A 3D high-resolution magnetization-prepared rapid gradient echo acquisition was performed for hippocampal volume measurements. Hippocampal volume was measured with FreeSurfer software (version 5.3) and adjusted for the total intracranial volume $(\mathrm{HVa})$ by calculating the residual from a linear regression of hippocampal volume vs the total intracranial volume. Hippocampal atrophy was determined from the upper 10th percentile of the HVa measurement distributions in patients with clinically diagnosed $\mathrm{AD}$ dementia in a previous study from an independent cohort. ${ }^{17}$ In a secondary analysis, we derived the HVa cutoff for hippocampal atrophy using the upper 10th percentile of the HVa measurement from the $\mathrm{AD}$ converters in our sample.

Statistical analysis. We summarized baseline characteristics of the patients using median (interquartile range) for continuous variables and count (percent) for categorical variables. Because there are 2 competing outcomes of interest, $\mathrm{AD}$ dementia and probable DLB, standard survival methods would not be appropriate and would likely give biased results. We used a proportional subdistribution hazards regression survival model considering competing risks, ${ }^{18}$ implemented in the $\mathrm{R}$ package cmprsk. We estimated the cumulative incidence of either clinically probable DLB or AD dementia in 2 groups: those with and without hippocampal atrophy. Because age is a significant driver of progression to dementia, age was used as the time scale for tighter control of age effects. We summarized the results of the competing risk models using $p$ values and subdistribution hazard ratios from product-limit methods to estimate the probability of a particular dementia outcome at a moment in time, given that the particular dementia has not occurred thus far. We plotted the cumulative probabilities of $\mathrm{AD}$ or probable DLB in the groups with and without hippocampal atrophy, using an age range covering the youngest (48.8) to oldest (90.5) ages with an event. A similar approach using a multivariate model was used to determine the contributions of hippocampal volume plus MCI subtype (MCI with nonamnestic impairments vs amnestic MCI single-domain) and contributions of hippocampal volume plus presence of clinical features (RBD, parkinsonism, visual hallucinations, and fluctuations) in predicting competing risks of probable $\mathrm{DLB}$ and $\mathrm{AD}$ dementia. 
RESULTS Characteristics of the study cohort at baseline are listed in table 1. After a median (range) follow-up of $2.03(0.69-8.10)$ years, patients with MCI progressed to $\mathrm{AD}$ dementia $(\mathrm{n}=61 ; 38 \%)$, probable DLB $(\mathrm{n}=20 ; 13 \%)$, or other dementias $(\mathrm{n}=14 ; 9 \%)$ such as frontotemporal dementia $(\mathrm{n}=$ 4), multiple system atrophy ( $\mathrm{n}=1)$, progressive nonfluent aphasia $(\mathrm{n}=3)$, semantic dementia $(\mathrm{n}=$ 2), logopenic progressive aphasia $(n=1)$, posterior cortical atrophy $(\mathrm{n}=1)$, or corticobasal syndrome $(\mathrm{n}=2)$, or died $(\mathrm{n}=3 ; 2 \%)$. Because $\mathrm{AD}$ dementia and probable DLB were the 2 competing outcomes of interest, patients with MCI who died or progressed to other dementia were censored at the time of progression to dementia or death. The $\mathrm{AD}$ dementia progressor group had a higher frequency of women $(p=0.005)$ and $A P O E$ \&4 carriers than the probable DLB progressor group $(p=0.004)$. The $\mathrm{AD}$ dementia progressor group had lower median Dementia Rating Scale score at baseline compared to the probable DLB progressor group $(p=0.02)$, but the Mini-Mental State Examination scores were similar $(p=0.53)$.
Whereas a majority of the patients with MCI were diagnosed with amnestic MCI single-domain ( $\mathrm{n}=$ 89; 56\%), amnestic MCI multiple-domain $(\mathrm{n}=$ $34 ; 21 \%)$ and nonamnestic MCI $(\mathrm{n}=37 ; 23 \%)$ were less frequent at baseline. Half of the patients with MCI who progressed to probable DLB were diagnosed with nonamnestic MCI ( $\mathrm{n}=10 ; 50 \%)$; on the contrary, a majority of patients with $\mathrm{MCI}$ who progressed to $\mathrm{AD}$ dementia were diagnosed with amnestic MCI single-domain $(n=42 ; 69 \%)$ at baseline. Clinical features of DLB were present in a majority of patients with MCI who progressed to probable DLB $(\mathrm{n}=19 ; 95 \%)$ and some had 2 or more $(\mathrm{n}=16$; $80 \%)$ or 3 or more $(n=9 ; 45 \%)$ of these clinical features present at baseline. On the contrary, a few of the patients with $\mathrm{MCI}$ who progressed to $\mathrm{AD}$ dementia had $1(n=7 ; 11 \%)$ and none had 2 of the clinical features of DLB present at baseline. HVa were smaller in the $\mathrm{AD}$ dementia progressor group compared to the DLB progressor group at baseline $(p<0.001)$ (figure 1). Whereas a majority of the patients with MCI who progressed to probable DLB had normal

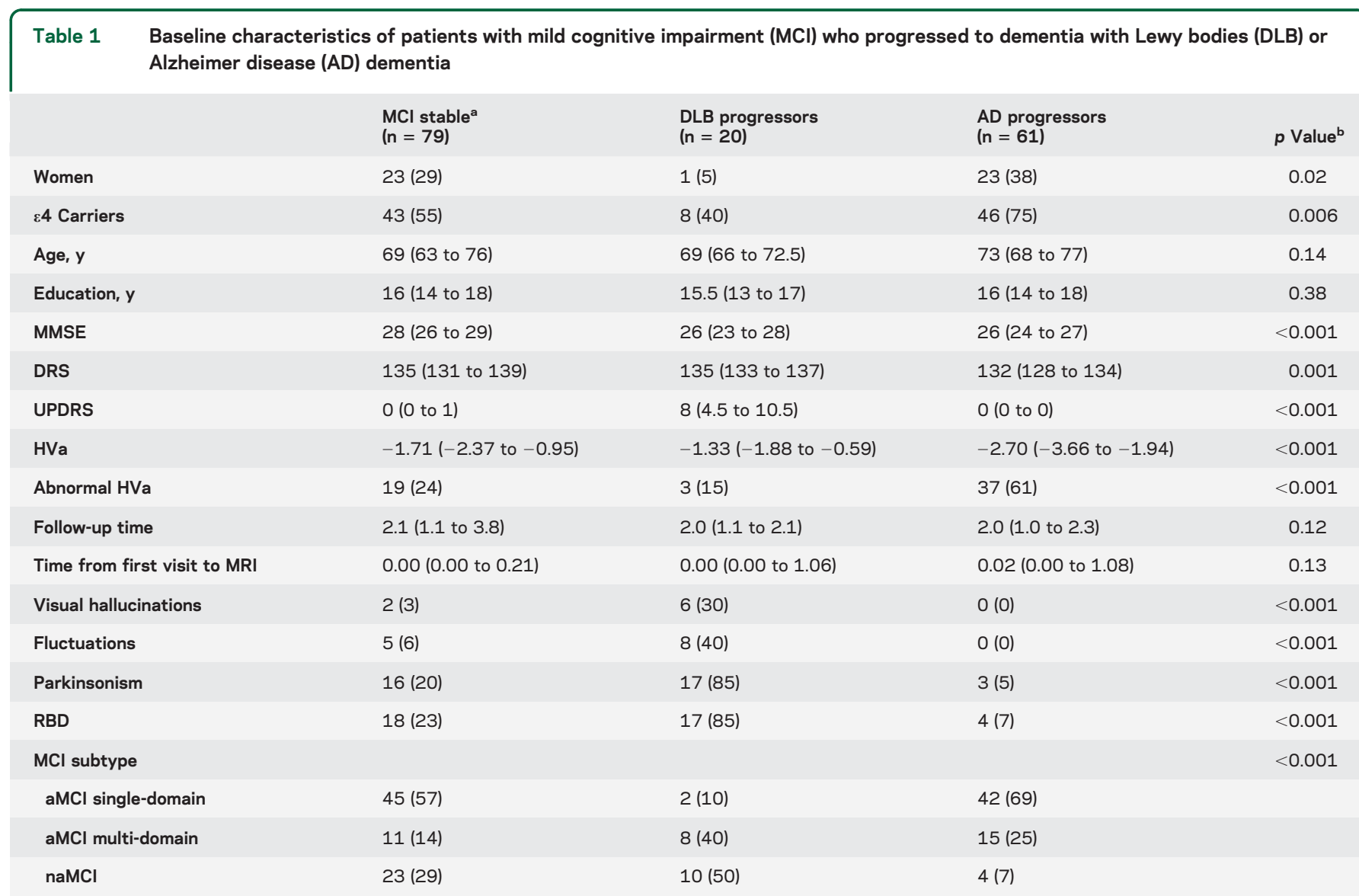

Abbreviations: aMCI = amnestic mild cognitive impairment; DRS = Dementia Rating Scale; HVa = hippocampal volume adjusted for total intracranial volume; MMSE = Mini-Mental State Examination; naMCI = nonamnestic mild cognitive impairment; RBD = REM sleep behavior disorder; UPDRS = Unified Parkinson's Disease Rating Scale part III.

Values represent median (interquartile range) or $\mathrm{n}(\%)$.

a Patients with $\mathrm{MCl}$ who remained stable or were censored at the time of death or progression to dementia syndromes other than DLB or AD dementia. ${ }^{\mathrm{b}} \mathrm{p}$ Values are from a Kruskal-Wallis test or Wilcoxon rank sum test for the continuous variables or a $\chi^{2}$ test of differences in proportions for the categorical variables among the clinical groups. 
$\mathrm{HVa}(\mathrm{n}=17 ; 85 \%)$, a majority of patients with MCI who progressed to $\mathrm{AD}$ dementia had hippocampal atrophy ( $\mathrm{n}=37 ; 61 \%$ ) using the previously published cutoff. ${ }^{17}$

Proportional hazards models for the HVa predicting competing risks of $\mathrm{AD}$ dementia vs probable $\mathrm{DLB}$ showed that patients with MCI with preserved HVa had a higher risk of progression to probable DLB (competing with $\mathrm{AD}$ dementia) relative to those with hippocampal atrophy with estimated subdistribution hazard ratio of $5.8(1.86-18.0 ; p=0.002)$. On the contrary, patients with MCI with preserved HVa had a lower risk of progression to $\mathrm{AD}$ dementia (competing with probable DLB) relative to those with hippocampal atrophy with estimated subdistribution hazard ratio of $0.56(0.34-0.91 ; p=0.02)$. Curves showing the probability of competing risk of progression to $\mathrm{AD}$ dementia and probable DLB are displayed in figure 2. We constructed multivariate models to determine whether hippocampal volumes provide information on probable DLB and $\mathrm{AD}$ risk when adjusting for MCI subtype. We investigated patients with MCI who had impairments in nonamnestic cognitive domains (i.e., nonamnestic MCI and amnestic MCI multiple-domain) compared to amnestic MCI single-domain, and normal HVa compared to atrophic $\mathrm{HVa}$ as predictors of probable DLB and AD dementia risk. In model 1 , multidomain-amnestic

\section{Figure 1 Hippocampal volumes adjusted for total intracranial volume (HVa) in} patients with mild cognitive impairment $(\mathrm{MCl})$

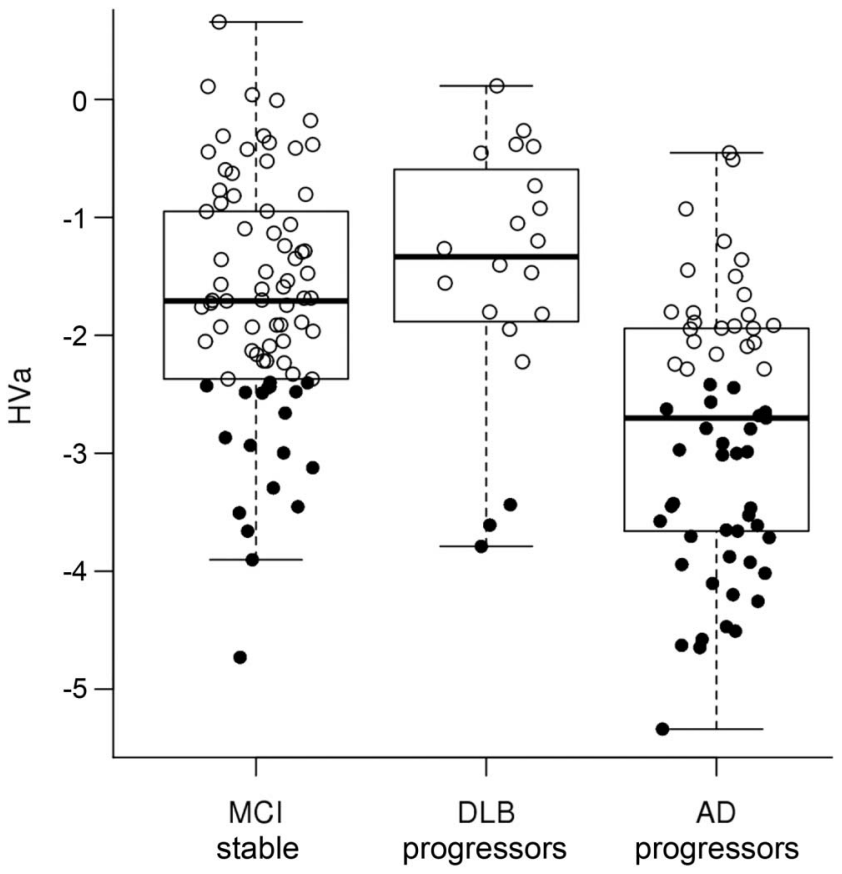

$\mathrm{HVa}$ in patients with $\mathrm{MCl}$ who did not progress to Alzheimer disease (AD) or dementia with Lewy bodies (DLB), patients with $\mathrm{MCl}$ who progressed to DLB, and patients with $\mathrm{MCl}$ who progressed to AD during follow-up. Dark circles indicate those labeled as having abnormal HVa for the survival analysis.
MCI $(p=0.002)$, and nonamnestic $\operatorname{MCI}(p=$ $0.0003)$ compared to single-domain amnestic MCI and normal $\mathrm{HVa}$ compared to atrophic $\mathrm{HVa}(p=$ 0.02 ) increased the risk of progressing to probable $\mathrm{DLB}$, accounting for competing $\mathrm{AD}$ dementia. In model 2, we combined the multidomain-amnestic MCI and nonamnestic MCI groups into one group of patients with MCI having impairments in nonamnestic cognitive domains. MCI with impairments in nonamnestic cognitive domains ( $p=0.0003)$ compared to single-domain amnestic MCI and normal $\mathrm{HVa}$ compared to atrophic $\mathrm{HVa}(p=0.01)$ increased the risk of progressing to probable DLB accounting for competing $\mathrm{AD}$ dementia. The individual subdistribution hazard ratios for the 2 models are listed in table 2. In a secondary analysis, we used the HVa cutoff (upper 10th percentile) for hippocampal preservation or atrophy derived from the $\mathrm{AD}$ progressor MCIs in our cohort and the results did not change (table e-1 at Neurology.org).

Presence of core and suggestive clinical features of DLB as predictors was tested in a separate multivariate model to determine whether hippocampal volumes provide information on probable DLB and $\mathrm{AD}$ risk when adjusting for presence of these clinical features of DLB in patients with MCI. MCI with a clinical feature of DLB (RBD, parkinsonism, visual hallucinations, and fluctuations) compared to MCI without any one of these features $(p<0.001)$ and normal HVa compared to atrophic $\mathrm{HVa}(p=0.048)$ increased the risk of progressing to probable DLB accounting for competing $\mathrm{AD}$ dementia (table e-2).

DISCUSSION In patients with MCI, preservation of hippocampal volumes was associated with a higher risk of progression to probable DLB, competing with the risk of progression to $\mathrm{AD}$ dementia. Competing risk analysis assumes that a patient with MCI who progresses to dementia will progress to either probable DLB or AD. Therefore the subdistribution hazard ratios for a dementia outcome are estimated by using the other dementia outcome as a competing risk. Patients with MCI with preserved hippocampal volumes had a hazard risk of progression to probable DLB 5.8 times that of those with hippocampal atrophy, when accounting for competing risk of progression to $\mathrm{AD}$ dementia. Furthermore, preserved hippocampal volumes predicted the hazard risk of progression to probable DLB along with the diagnosis of MCI with impairments in nonamnestic cognitive domains with or without memory impairment.

Hippocampal atrophy is associated with a higher risk of progression to $\mathrm{AD}$ dementia in patients with MCI. ${ }^{19}$ Based on these observations, hippocampal atrophy is included in the research criteria to support the diagnosis of MCI due to $\mathrm{AD}^{2}$ However, the 
Figure 2 Cumulative incidences of progression to dementia with Lewy bodies

(DLB) and Alzheimer disease (AD)

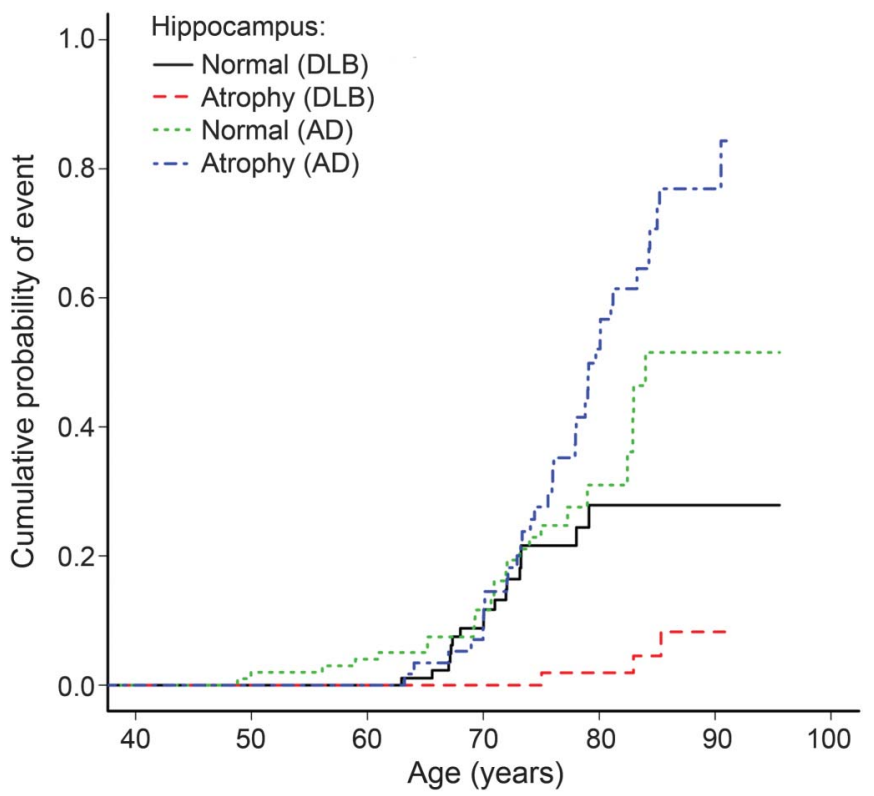

Cumulative incidences of progression to $D L B$ and $A D$ in patients with mild cognitive impairment by normal (preserved) hippocampus vs hippocampal atrophy. Hippocampal volumes are adjusted for total intracranial volume. Age is used as the timescale.

underlying etiologies of MCI, broadly defined with impairments in amnestic or nonamnestic cognitive domains, are heterogeneous. ${ }^{1}$ Both vascular and Lewy body disease may contribute to the cognitive difficulties in patients with MCI. ${ }^{20,21}$ Furthermore, hippocampal volumes may be relatively preserved in patients with $\mathrm{MCI}$, particularly in those with nonamnestic MCI. ${ }^{22}$

In the current study, preserved hippocampal volumes predicted progression to DLB accounting for the competing risk for progression to $\mathrm{AD}$ dementia, even after considering nonamnestic MCI compared to amnestic MCI single-domain diagnosis. Impairment

\begin{tabular}{|c|c|c|c|}
\hline Table 2 & \multicolumn{3}{|c|}{$\begin{array}{l}\text { Multivariable model including hippocampal volume and mild cognitive } \\
\text { impairment }(\mathrm{MCl}) \text { subtype }\end{array}$} \\
\hline Outcome & Predictors & $\begin{array}{l}\text { Subdistribution HR } \\
(95 \% \mathrm{Cl})\end{array}$ & $p$ Value \\
\hline \multirow[t]{3}{*}{ Model 1} & Preserved $\mathrm{HVa}$ vs atrophic $\mathrm{HVa}$ & $4.46(1.27-15.67)$ & 0.0200 \\
\hline & aMCl-MD vs aMCI-SD & $12.84(2.59-63.65)$ & 0.0018 \\
\hline & naMCl vs aMCl-SD & $11.21(2.96-42.38)$ & 0.0003 \\
\hline \multirow[t]{2}{*}{ Model 2} & Preserved $\mathrm{HVa}$ vs atrophic $\mathrm{HVa}$ & $4.22(1.42-12.6)$ & 0.0098 \\
\hline & aMCI-MD plus naMCla vs aMCI-SD & $11.96(3.08-46.46)$ & 0.0003 \\
\hline
\end{tabular}

Abbreviations: aMCI-MD = amnestic mild cognitive impairment-multiple-domain; aMCl-SD = amnestic mild cognitive impairment-single-domain; $\mathrm{Cl}$ = confidence interval; $\mathrm{HR}$ = hazard ratio; $\mathrm{HVa}=$ total intracranial volume-adjusted hippocampal volume; naMCl = nonamnestic mild cognitive impairment.

Subdistribution hazard ratio is reported for dementia with Lewy bodies progression accounting for competing Alzheimer disease progression.

${ }^{a} \mathrm{MCl}$ with impairments in nonamnestic cognitive domains. in nonamnestic cognitive domains, particularly in the attention and visual-spatial processing domains, increases the risk for probable DLB in MCI. ${ }^{4,5,23}$ While nonamnestic MCI is characterized by relative preservation of hippocampal volumes, hippocampal atrophy may be present in some patients with nonamnestic MCI. ${ }^{22}$ Furthermore, hippocampal atrophy is common in patients with multiple-domain amnestic MCI, and these patients are at risk for both probable DLB and $\mathrm{AD}$ dementia. ${ }^{3,520,23}$ Thus, the distinction of patients with MCI who will progress to DLB vs $\mathrm{AD}$ dementia may not be clear only by the MCI subtype. Data from the current study suggest that hippocampal volumes predict progression to probable DLB along with the MCI subtype.

Relative preservation of medial temporal lobe structures is a supportive feature in the 3rd report of the DLB Consortium Criteria, categorized as a feature that is commonly present in DLB. ${ }^{13}$ However, as a supportive feature, preservation of hippocampal volume does not contribute to the diagnosis of probable DLB, which is made based on presence of 2 or more core and suggestive features. ${ }^{24}$ In particular, hippocampal atrophy suggests additional AD-related neurofibrillary tangle pathology in probable DLB cases and may differentiate patients with mixed $\mathrm{AD}$ and Lewy body disease pathology from those with DLB. ${ }^{6-9}$ Preservation of hippocampal volumes is also observed in patients with hippocampal sparing $\mathrm{AD},{ }^{25}$ therefore is not specific to DLB. We censored individuals who progressed to dementia syndromes other than $\mathrm{AD}$ dementia or probable DLB at the time of progression to dementia and several of these patients as well as those who received a clinical diagnosis of probable DLB or $\mathrm{AD}$ dementia may have had atypical $\mathrm{AD}$ pathology. ${ }^{26,27}$ Preservation of hippocampal volume in cases of atypical $\mathrm{AD}$ dementia may decrease the specificity of preserved hippocampal volumes in predicting progression to probable DLB in MCI. Furthermore, absence of hippocampal atrophy might have rather low positive predictive value in cognitively normal individuals; therefore the application would be limited to patients with MCI.

There are limitations to our study that need to be addressed. First, the study cohort was from an Alzheimer Disease Research Center-based dementia clinic sample, which was relatively small and is prone to ascertainment biases. Epidemiologic studies that examine the transition from MCI to probable DLB and the role of biomarkers in predicting this transition are needed. Furthermore, the outcomes of interest were clinical diagnosis of probable DLB or $\mathrm{AD}$ dementia. The clinical criteria for the diagnosis of DLB are criticized for having low sensitivity. ${ }^{28,29}$ Moreover, patients who fulfill the clinical criteria for probable DLB may have additional AD pathology and Lewy body disease pathology may be present in 
patients with $\mathrm{AD}$ dementia. Thus, many of our cases may have mixed $\mathrm{AD}$ and Lewy body disease pathologies. Pathologic confirmation of the diagnosis of DLB and $\mathrm{AD}$ is critical. Many of the patients with MCI had one or more of the core and suggestive features of probable DLB. We found that hippocampal volumes may be predictive of DLB vs $\mathrm{AD}$ diagnosis in addition to these clinical features. However, this finding should be interpreted with caution, because DLB competing with $\mathrm{AD}$ diagnosis was predicted based on the very features that are used for diagnosing probable DLB, and addition of the clinical features to the models introduced multicollinearity due to correlations among the predictors. An autopsy-confirmed and longitudinally followed cohort of patients with MCI is needed to determine the sensitivity and specificity of the core and suggestive clinical features of Lewy body disease at the stage of MCI.,30 Finally, approximately $49 \%$ of the patients with MCI in our cohort were stable during follow-up. It is expected that there will be patients who progress to probable DLB or $\mathrm{AD}$ dementia from the $\mathrm{MCI}$ stable group in the future.

In a cohort of consecutive patients with MCI from a referral clinic, we demonstrated that those with preserved hippocampal volumes are at an increased risk for probable DLB, competing with the risk of progression to $\mathrm{AD}$ dementia, even after considering the $\mathrm{MCI}$ subtype. Therefore both nonamnestic features and hippocampal preservation may be considered for identifying patients with MCI at risk for probable DLB. Better response to cholinesterase inhibitors and neuroleptic sensitivity may need to be addressed in patients with MCI who are likely to progress to probable DLB.

\section{AUTHOR CONTRIBUTIONS}

Dr. Kantarci: study concept and design, acquisition of data, analysis and interpretation of the data, drafting the manuscript. T. Lesnick: study concept and design, analysis or interpretation of the data, critical revision of the manuscript for important intellectual content. Dr. Ferman: study concept and design, acquisition of data, critical revision of the manuscript for important intellectual content. S.A. Przybelski: study concept and design, analysis or interpretation of the data, critical revision of the manuscript for important intellectual content. Dr. Boeve: acquisition of data, critical revision of the manuscript for important intellectual content. Dr. Smith: acquisition of data, critical revision of the manuscript for important intellectual content. Dr. Kremers: study concept and design, analysis or interpretation of the data, critical revision of the manuscript for important intellectual content. Dr. Knopman: acquisition of data, critical revision of the manuscript for important intellectual content. Dr. Jack: acquisition of data, analysis and interpretation of the data, critical revision of the manuscript for important intellectual content. Dr. Petersen: acquisition of data, critical revision of the manuscript for important intellectual content.

\section{STUDY FUNDING}

NIH (R01 AG040042, R01 AG11378, P50 AG16574, U01 AG06786, C06 RR018898), Mangurian Foundation, and the Robert H. and Clarice Smith and Abigail Van Buren Alzheimers Disease Research Program.

\section{DISCLOSURE}

K. Kantarci serves on the Data Safety Monitoring Board for Takeda Global Research \& Development Center, Inc.; data monitoring boards of Pfizer and Janssen Alzheimer Immunotherapy; and is funded by the NIH (R01 AG040042 [PI], R21 NS066147 [PI], P50 AG44170/Project 2 [PI], P50 AG16574/Project 1 [PI], and R01 AG11378 [Co-I]). T. Lesnick reports no disclosures relevant to the manuscript. T. Ferman is funded by the NIH (P50-AG16574) and the Mangurian Foundation. S. Przybelski reports no disclosures relevant to the manuscript. B. Boeve has served as an investigator for clinical trials sponsored by GE Healthcare and FORUM Pharmaceuticals; receives royalties from the publication of a book titled Behavioral Neurology of Dementia (Cambridge Medicine, 2009); serves on the Scientific Advisory Board of the Tau Consortium; has consulted for Isis Pharmaceuticals; and receives research support from the NIH (U01 AG045390, U54 NS092089, P50 AG016574, UO1 AG006786, RO1 AG015866, RO1 AG032306, RO1 AG041797) and the Mangurian Foundation. G. Smith is funded by the NIH. W. Kremers is funded by the NIH. D. Knopman served as Deputy Editor for Neurology ${ }^{\circledR}$; served on a Data Safety Monitoring Board for Lilly Pharmaceuticals; serves on a Data Safety Monitoring Board for Lundbeck Pharmaceuticals and for the DIAN study; served as a consultant to TauRx Pharmaceuticals ending in November 2012; was an investigator in clinical trials sponsored by Baxter and Elan Pharmaceuticals in the past 2 years; is currently an investigator in a clinical trial sponsored by TauRx; and receives research support from the NIH. C. Jack serves as a consultant for Janssen, Bristol-Meyer-Squibb, General Electric, and Johnson \& Johnson; is involved in clinical trials sponsored by Allon and Baxter, Inc; and receives research support from Pfizer, Inc., the NIA (AG11378 [PI], P50-AG16574 [Co-I], and U01-AG024904-01 [Co-I]), and the Alexander Family Alzheimer's Disease Research Professorship of the Mayo Foundation. R. Petersen serves on scientific advisory boards for Elan Pharmaceuticals, Wyeth Pharmaceuticals, and GE Healthcare and receives research support from the NIH (P50-AG16574 [PI] and U01-AG06786 [PI], R01-AG11378 [Co-I], and U01-24904 [Co-I]). Go to Neurology.org for full disclosures.

Received September 28, 2015. Accepted in final form August 24, 2016.

\section{REFERENCES}

1. Petersen RC, Smith GE, Waring SC, Ivnik RJ, Tangalos EG, Kokmen E. Mild cognitive impairment: clinical characterization and outcome. Arch Neurol 1999;56:303-308.

2. Albert MS, DeKosky ST, Dickson D, et al. The diagnosis of mild cognitive impairment due to Alzheimer's disease: recommendations from the National Institute on AgingAlzheimer's Association workgroups on diagnostic guidelines for Alzheimer's disease. Alzheimers Dement 2011;7: 270-279.

3. Molano J, Boeve B, Ferman T, et al. Mild cognitive impairment associated with limbic and neocortical Lewy body disease: a clinicopathological study. Brain 2010;133: 540-556.

4. Yoon JH, Kim M, Moon SY, Yong SW, Hong JM. Olfactory function and neuropsychological profile to differentiate dementia with Lewy bodies from Alzheimer's disease in patients with mild cognitive impairment: a 5-year followup study. J Neurol Sci 2015;355:174-179.

5. Ferman TJ, Smith GE, Kantarci K, et al. Nonamnestic mild cognitive impairment progresses to dementia with Lewy bodies. Neurology 2013;81:2032-2038.

6. Burton EJ, Mukaetova-Ladinska EB, Perry RH, Jaros E, Barber R, O'Brien JT. Neuropathological correlates of volumetric MRI in autopsy-confirmed Lewy body dementia. Neurobiol Aging 2012;33:1228-1236.

7. Kantarci K, Ferman TJ, Boeve BF, et al. Focal atrophy on MRI and neuropathologic classification of dementia with Lewy bodies. Neurology 2012;79:553-560.

8. Nedelska Z, Ferman TJ, Boeve BF, et al. Pattern of brain atrophy rates in autopsy-confirmed dementia with Lewy bodies. Neurobiol Aging 2015;36:452-461. 
9. Murray ME, Ferman TJ, Boeve BF, et al. MRI and pathology of REM sleep behavior disorder in dementia with Lewy bodies Neurology 2013;81:1681-1689.

10. Petersen RC. Mild cognitive impairment as a diagnostic entity. J Intern Med 2004;256:183-194.

11. McKhann G, Drachman D, Folstein M, Katzman R, Price D, Stadlan EM. Clinical diagnosis of Alzheimer's disease: report of the NINCDS-ADRDA work group under the auspices of department of health and human services task force on Alzheimer's disease. Neurology 1984;34:939-944.

12. McKhann GM, Knopman DS, Chertkow H, et al. The diagnosis of dementia due to Alzheimer's disease: recommendations from the National Institute on Aging-Alzheimer's Association workgroups on diagnostic guidelines for Alzheimer's disease. Alzheimers Dement 2011;7:263-269.

13. McKeith IG, Dickson DW, Lowe J, et al. Diagnosis and management of dementia with Lewy bodies: third report of the DLB Consortium. Neurology 2005;65:1863-1872.

14. Ferman TJ, Smith GE, Boeve BF, et al. DLB fluctuations: specific features that reliably differentiate DLB from AD and normal aging. Neurology 2004;62:181-187.

15. Boeve BF, Molano JR, Ferman TJ, et al. Validation of the Mayo sleep Questionnaire to screen for REM sleep behavior disorder in a community-based sample. J Clin Sleep Med 2013;9:475-480.

16. AASM. International Classification of Sleep Disorders 2: Diagnostic and Coding Manual. Chicago: American Academy of Sleep Medicine; 2005.

17. Jack CR Jr, Knopman DS, Weigand SD, et al. An operational approach to National Institute on Aging-Alzheimer's Association criteria for preclinical Alzheimer disease. Ann Neurol 2012;71:765-775.

18. Fine JP, Gray RJ. A proportional hazards model for the subdistribution of a competing risk. JASA 1999;94:496-509.

19. Jack CR Jr, Petersen RC, Xu YC, et al. Prediction of AD with MRI-based hippocampal volume in mild cognitive impairment. Neurology 1999;52:1397-1403.

20. Jicha GA, Parisi JE, Dickson DW, et al. Neuropathologic outcome of mild cognitive impairment following progression to clinical dementia. Arch Neurol 2006;63:674-681.
21. Schneider JA, Arvanitakis Z, Leurgans SE, Bennett DA. The neuropathology of probable Alzheimer disease and mild cognitive impairment. Ann Neurol 2009;66: 200-208.

22. Kantarci K, Petersen RC, Przybelski SA, et al. Hippocampal volumes, proton magnetic resonance spectroscopy metabolites, and cerebrovascular disease in mild cognitive impairment subtypes. Arch Neurol 2008;65:1621-1628.

23. Belden CM, Kahlon V, Malek-Ahmadi M, Tsai A, Sabbagh $\mathrm{MN}$. Clinical characterization of mild cognitive impairment as a prodrome to dementia with Lewy bodies. Am J Alzheimers Dis Other Demen 2015;30:173-177.

24. McKeith IG, Galasko D, Kosaka K, et al. Consensus guidelines for the clinical and pathologic diagnosis of dementia with Lewy bodies (DLB): report of the Consortium on DLB International Workshop. Neurology 1996; 47:1113-1124.

25. Whitwell JL, Dickson DW, Murray ME, et al. Neuroimaging correlates of pathologically defined subtypes of Alzheimer's disease: a case-control study. Lancet Neurol 2012;11:868-877.

26. Galton CJ, Patterson K, Xuereb JH, Hodges JR. Atypical and typical presentations of Alzheimer's disease: a clinical, neuropsychological, neuroimaging and pathological study of 13 cases. Brain 2000;3:484-498. 123 Pt.

27. Murray ME, Graff-Radford NR, Ross OA, Petersen RC, Duara R, Dickson DW. Neuropathologically defined subtypes of Alzheimer's disease with distinct clinical characteristics: a retrospective study. Lancet Neurol 2011;10:785-796.

28. Aarsland D, Rongve A, Nore SP, et al. Frequency and case identification of dementia with Lewy bodies using the revised consensus criteria. Dement Geriatr Cogn Disord 2008;26:445-452.

29. Nelson PT, Jicha GA, Kryscio RJ, et al. Low sensitivity in clinical diagnoses of dementia with Lewy bodies. J Neurol 2010;257:359-366.

30. Jicha GA, Schmitt FA, Abner E, et al. Prodromal clinical manifestations of neuropathologically confirmed Lewy body disease. Neurobiol Aging 2010;31:1805-1813.

\section{Registration Now Open for 2017 AAN Annual Meeting in Boston}

Discover the Annual Meeting everyone's talking about. We changed the entire format and feel of the AAN Annual Meeting for 2016 - and people took notice! We're doing it again in 2017, and adding even more changes to the docket. Register today to experience the value, choice, customization, and innovation that only an AAN Annual Meeting can offer. We look forward to seeing you April 22-28 in Boston. Register today at AAN.com/view/AM17. 


\section{Neurology}

Hippocampal volumes predict risk of dementia with Lewy bodies in mild cognitive impairment

Kejal Kantarci, Timothy Lesnick, Tanis J. Ferman, et al.

Neurology 2016;87;2317-2323 Published Online before print November 2, 2016

DOI 10.1212/WNL.0000000000003371

This information is current as of November 2, 2016

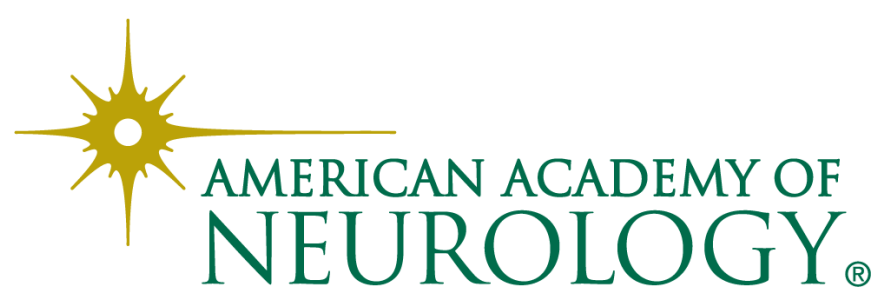




\section{Updated Information \& Services}

\section{Supplementary Material}

References

Citations

Subspecialty Collections

Permissions \& Licensing

\section{Reprints}

including high resolution figures, can be found at: http://n.neurology.org/content/87/22/2317.full

Supplementary material can be found at: http://n.neurology.org/content/suppl/2016/11/02/WNL.0000000000003 371.DC1

This article cites 29 articles, 8 of which you can access for free at: http://n.neurology.org/content/87/22/2317.full\#ref-list-1

This article has been cited by 3 HighWire-hosted articles: http://n.neurology.org/content/87/22/2317.full\#\#otherarticles

This article, along with others on similar topics, appears in the following collection(s):

Alzheimer's disease

http://n.neurology.org/cgi/collection/alzheimers_disease

Dementia with Lewy bodies

http://n.neurology.org/cgi/collection/dementia_with_lewy_bodies

MCI (mild cognitive impairment)

http://n.neurology.org/cgi/collection/mci_mild_cognitive_impairment

\section{MRI}

http://n.neurology.org/cgi/collection/mri

Volumetric MRI

http://n.neurology.org/cgi/collection/volumetric_mri

Information about reproducing this article in parts (figures,tables) or in its entirety can be found online at:

http://www.neurology.org/about/about_the_journal\#permissions

Information about ordering reprints can be found online:

http://n.neurology.org/subscribers/advertise

Neurology ${ }^{\circledR}$ is the official journal of the American Academy of Neurology. Published continuously since 1951, it is now a weekly with 48 issues per year. Copyright @ 2016 American Academy of Neurology. All rights reserved. Print ISSN: 0028-3878. Online ISSN: 1526-632X.

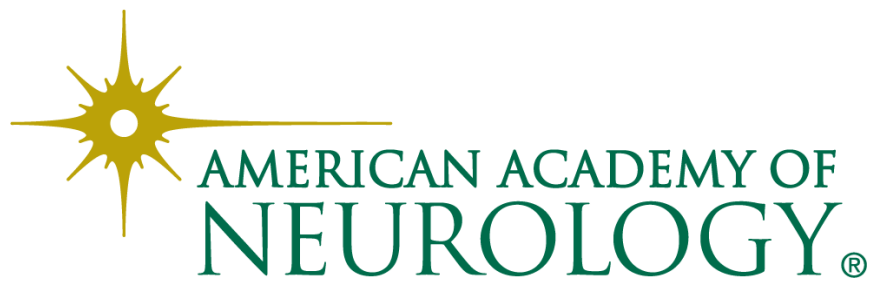

